Article

\title{
ESM-1 Overexpression is Involved in Increased Tumorigenesis of Radiotherapy-Resistant Breast Cancer Cells
}

\author{
Hana Jin ${ }^{1,+}$, Trojan Rugira ${ }^{1,2,+}$, Young Shin Ko ${ }^{1}$, Sang Won Park ${ }^{1,2} \mathbb{C}^{\text {, Seung Pil Yun }}{ }^{1}$ and \\ Hye Jung Kim 1,2,*D \\ 1 Department of Pharmacology, College of Medicine, Institute of Health Sciences, Gyeongsang National \\ University, Jinju 52727, Korea; hanajin.kr@daum.net (H.J.); rugirawacu@gmail.com (T.R.); \\ shini33@naver.com (Y.S.K.); parksw@gnu.ac.kr (S.W.P.); spyun@gnu.ac.kr (S.P.Y.) \\ 2 Department of Convergence Medical Science (BK21 Plus), Gyeongsang National University, \\ Jinju 52727, Korea \\ * Correspondence: hyejungkim@gnu.ac.kr; Tel.: +82-55-772-8074; Fax: +82-55-772-8079 \\ + These authors contributed equally to this work.
}

Received: 14 April 2020; Accepted: 22 May 2020; Published: 26 May 2020

\begin{abstract}
The key barrier to the effectiveness of radiotherapy remains the radioresistance of breast cancer cells, resulting in increased tumor recurrence and metastasis. Thus, in this study, we aimed to clarify the difference between radiotherapy-resistant (RT-R) breast cancer (BC) and BC, and accordingly, analyzed gene expression levels between radiotherapy-resistant (RT-R) MDA-MB-231 cells and MDA-MB-231 cells. Gene expression array showed that ESM-1 was the most upregulated in RT-R-MDA-MB-231 cells compared to MDA-MB-231 cells. Then, we aimed to investigate the role of ESM-1 in the increased tumorigenesis of RT-R-BC cells. RT-R-MDA-MB-231, which showed an increased expression level of ESM1, exhibited significantly enhanced proliferation, colony forming ability, migration, and invasion compared to MDA-MB-231 cells, and ESM-1 knockdown effectively reversed these effects. In addition, compared to MDA-MB-231 cells, RT-R-MDA-MB-231 cells displayed improved adhesion to endothelial cells (ECs) due to the induction of adhesion molecules and increased MMP-9 activity and VEGF-A production, which were decreased by ESM-1 knockdown. Moreover, the expression of HIF- $1 \alpha$ and activation of NF- $\kappa$ B and STAT-3 were increased in RT-R-MDA-MB-231 cells compared to MDA-MB-231 cells, and these effects were abolished by the knockdown of ESM-1. Finally, we confirmed the role of ESM-1 in tumorigenesis in an in vivo mouse model. Tumor volume, lung metastasis, and tumorigenic molecules (VEGF-A, HIF-1 $\alpha$, MMP-9, ICAM-1, VCAM-1, and phospho-NF- $\kappa$ B and phospho-STAT-3) were significantly induced in mice injected with ESM-1-overexpressing 4T1 cells and greatly enhanced in those injected with ESM-1-overexpressing RT-R-4T1 cells. Taken together, these results suggest for the first time that ESM-1 plays a critical role in tumorigenesis of breast cancer cells, especially RT-R-breast cancer cells, through the induction of cell proliferation and invasion.
\end{abstract}

Keywords: ESM-1; metastasis; tumorigenesis; radiotherapy-resistant; TNBC

\section{Introduction}

Breast cancer (BC) is the most common cancer diagnosed in women worldwide. BC incidence is relatively high in North American and Western European women, but the incidence and mortality rates in Asian populations and low-income countries have been steadily increasing due to a lack of diagnostic and treatment programs [1,2]. BC is a diverse disease consisting of many subtypes, each of which carries a different molecular and pathologic profile. Triple negative breast cancer (TNBC) is a 
subtype of BC characterized by a lack of estrogen and progesterone receptors (ER/PR) expression and epidermal growth factor receptor 2 (HER2) expression. Epidemiologically, TNBC accounts for $12 \%$ to $18 \%$ of all BC cases. TNBC patients do not benefit from hormonal therapy due to the lack of receptor expression. Even though therapeutic methods including surgery, chemotherapy, and radiotherapy have been developed to treat cancer, TNBC patients easily develop therapeutic resistance and disease recurrence [3]. Radiotherapy (RT) is a method mostly used to treat solid cancers. Although RT has improved the lives of BC patients, some patients still develop tumor recurrence after completion of RT. Tumor recurrence after RT may be caused by aggressive tumor biology, the capacity of cancer cells to resist RT, such as the presence of cancer stem cells (CSCs) and hypoxic conditions, or the development of de novo resistance, leading to treatment failure [4].

In our previous study [5], we established radiotherapy-resistant (RT-R)-BC cells from TNBC cell (MDA-MB-231) and nonTNBC cells (MCF-8 and T47D) by repeated irradiation 25 times at 2 Gy to accumulate total dose of $50 \mathrm{~Gy}$, and then examined the properties of RT-R-BC cells. We found that RT-R-MDA-MB-231 cells, which are derived from highly metastatic MDA-MB-231 cells, showed most radio- and chemo-resistance of tested three cell lines (RT-R-MDA-MB-231, RT-R-MCF-7, and RT-R-T47D) and more increased protein levels of CSCs markers CD44, Notch-4, Oct3/4, and ALDH1, compared to other RT-R-BC cells. Moreover, compared to MDA-MB-231 cells, RT-R-MDA-MB-231 cells exhibited increased metastatic properties due to higher expression of ICAM-1 and VCAM-1, which promoted migration and adhesion to endothelial cells (ECs) and induced invasion through ECs by increasing MMP-9, Snail-1, and $\beta$-catenin production and decreasing E-cadherin [5]. Furthermore, we reported that RT-R-MDA-MB-231 cells produced more CSCs, and suggested CSCs may be the source of radioresistance and RT acquisition [5]. In addition, we have also showed that RT-R-MDA-MB-231 cells release higher levels of ATP than other BC cells, and the subsequent activation of P2Y purinergic receptor $2\left(\mathrm{P}_{2} \mathrm{Y}_{2} \mathrm{R}\right)$ by released ATP leads to tumor growth and invasion through inflammasome activation [6]. Therefore, in this study, we aimed to clarify the differential gene expression level between RT-R-MDA-MB-231 cells and MDA-MB-231 cells, which showed most radioresistance and metastatic properties and obtained the result showing that endothelial cell specific molecule-1 (ESM-1) was most upregulated in RT-R-MDA-MB-231 cells than in MDA-MB-231 cells.

ESM-1, also called endocan, is a 50-kDa secreted proteoglycan. ESM-1 is composed of a 165-amino acid mature polypeptide and one dermatan sulfate chain [7] and is secreted by diverse ECs [8]. ESM-1 secretion is upregulated by angiogenic factors such as VEGF or proinflammatory cytokines such as tumor necrosis factor (TNF $\alpha$ ), interleukin (IL)-1 $\beta$, and IFN $\gamma$ [9-12]. Moreover, a higher concentration of ESM-1 has been detected in the serum of patients with septic shock and sepsis than in the serum of healthy people $[10,13]$. Furthermore, a variety of studies have reported that a high level of ESM-1 secretion is found in several cancers, including lung cancer [14], kidney cancer [15,16], colorectal cancer [17], acute myeloid leukemia [18], glioblastomas [7], and BC [19]. Moreover, ESM-1 overexpression in human embryonic kidney 293 cells causes tumor formation and growth in SCID mice [20]. However, the role of ESM-1 in enhanced tumorigenesis in RT-R TNBC has not yet been reported. Therefore, in this study, we also aimed to investigate the role of ESM-1 overexpression in the tumorigenesis of RT-R-MDA-MB-231 BC cells.

\section{Results}

\subsection{ESM-1 is Significantly Overexpressed in RT-R-MDA-MB-231 Cells Compared with MDA-MB-231 Cells}

First, we analyzed gene expression levels between MDA-MB-231 and RT-R-MDA-MB-231 cells by gene expression array analysis, and we found that the ESM-1 mRNA level was most upregulated in RT-R-MDA-MB-231 cells than in MDA-MB-231 cells (Table 1). Then, we confirmed the expression levels of ESM-1 in MDA-MB-231 cells and RT-R-MDA-MB-231 cells in both mRNA level and protein level by RT-PCR and ELISA, respectively (Figure 1). The results confirmed that RT-R-MDA-MB-231 
cells showed higher expression levels of ESM-1 than MDA-MB-231 cells at both the mRNA and protein levels.

Table 1. Top 10 upregulated genes in RT-R-MDA-MB-231 compared to MDA-MB-231.

\begin{tabular}{cc}
\hline Gene Symbol & Fold Change (RT-R-MDA-MB-231 vs. MDA-MB-231) \\
\hline ESM1 & 318.75 \\
MMP1 & 203.77 \\
SEL1L3 & 131.56 \\
MAGEB2 & 118.04 \\
ALPK2 & 116.37 \\
LOC100134317 & 100.11 \\
PHGDH & 98.82 \\
LOC284412 & 97.10 \\
PLCB4 & 89.00 \\
PLCH2 & 82.37 \\
\hline
\end{tabular}

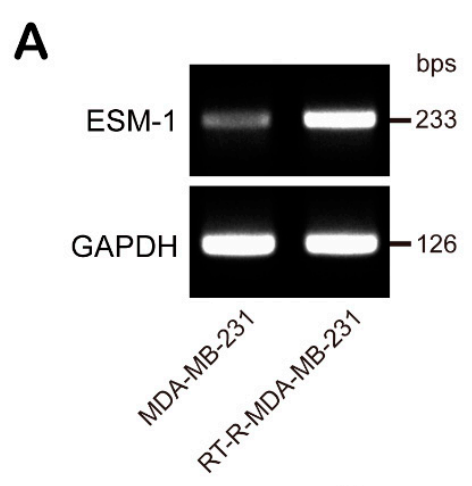

B

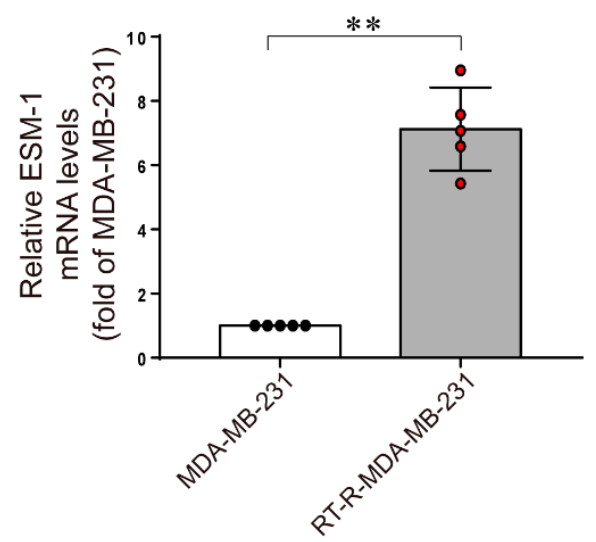

C

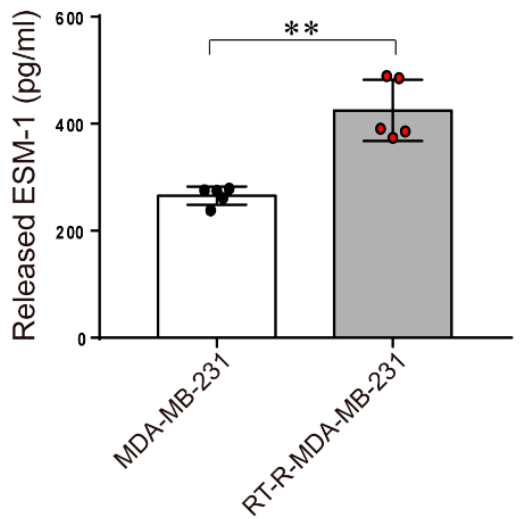

Figure 1. ESM-1 expression levels in MDA-MB-231 cells and their RT-R derivatives. (A,B) ESM-1 mRNA expression in RT-R-MDA-MB-231 cells and their parental cells, MDA-MB-231 was analyzed by RT-PCR. The full blot image can be found in Figure S1. Representative ESM-1 mRNA levels (A) and the quantification of ESM-1 mRNA levels (B) in MDA-MB-231 and RT-R-MDA-MB-231 cells. The data represent the mean $\pm \mathrm{SD}$ of five independent experiments. (C) Cells were incubated for $72 \mathrm{~h}$, and the levels of ESM-1 secreted by MDA-MB-231 and RT-R-MDA-MB-231 cells into cell culture medium were measured using ELISA kit for ESM-1 as described in the methods sections. The data represent the mean \pm SD of five independent experiments. ${ }^{*} p<0.05,{ }^{* *} p<0.01$.

2.2. ESM-1 Knockdown Inhibits the Proliferation, Colony Formation Ability, Migration, and Invasion of both MDA-MB-231 and RT-R-MDA-MB-231 Cells

Then, we investigated the effect of ESM-1 overexpression on the increased tumorigenesis of RT-R-MDA-MB-231 cells. First, we knocked down the ESM-1 gene in both MDA-MB-231 and 
RT-R-MDA-MB-231 cells by transfecting a small interfering RNA (siRNA) and confirmed the effectiveness of knockdown by RT-PCR (Figure 2A). Cell proliferation was evaluated by the Cell Counting Kit-8 (CCK-8) assay. RT-R-MDA-MB-231 cells demonstrated a higher cell proliferation ability (55\%) than their parental MDA-MB-231 cells, and this effect was significantly reduced by ESM-1 knockdown (Figure 2B). In addition, RT-R-MDA-MB-231 cells showed significantly enhanced ability to form colony compared to MDA-MB-231 cells, and this ability was significantly reduced by ESM-1 knockdown (Figure 2C,D). According to the report [21], during tumor metastasis, cancer cells migrate from their primary sites to invade new distant organs. Therefore, to evaluate the role of ESM- 1 in BC cell migration and invasion, ESM-1 was knocked down in both MDA-MB-231 and RT-R-MDA-MB-231 cells, and then cell migration and invasion were analyzed. Our results showed that the migration abilities of both MDA-MB-231 and RT-R-MDA-MB-231 cells transfected with ESM-1 siRNA were decreased more than 2-fold and 3-fold, compared to the migration abilities of those transfected with control (CTRL) siRNA, when they measured at $24 \mathrm{~h}$ and $48 \mathrm{~h}$, respectively (Figure 2E,F). Additionally, the invasion of RT-R-MDA-MB-231 cells through the EC-Matrigel-coated insert well membrane was 2.25-fold greater than that of MDA-MB-231 cells, and the invasion of both RT-R-MDA-MB-231 and MDA-MB-231 cells transfected with ESM siRNA was significantly reduced (Figure 2G,H).
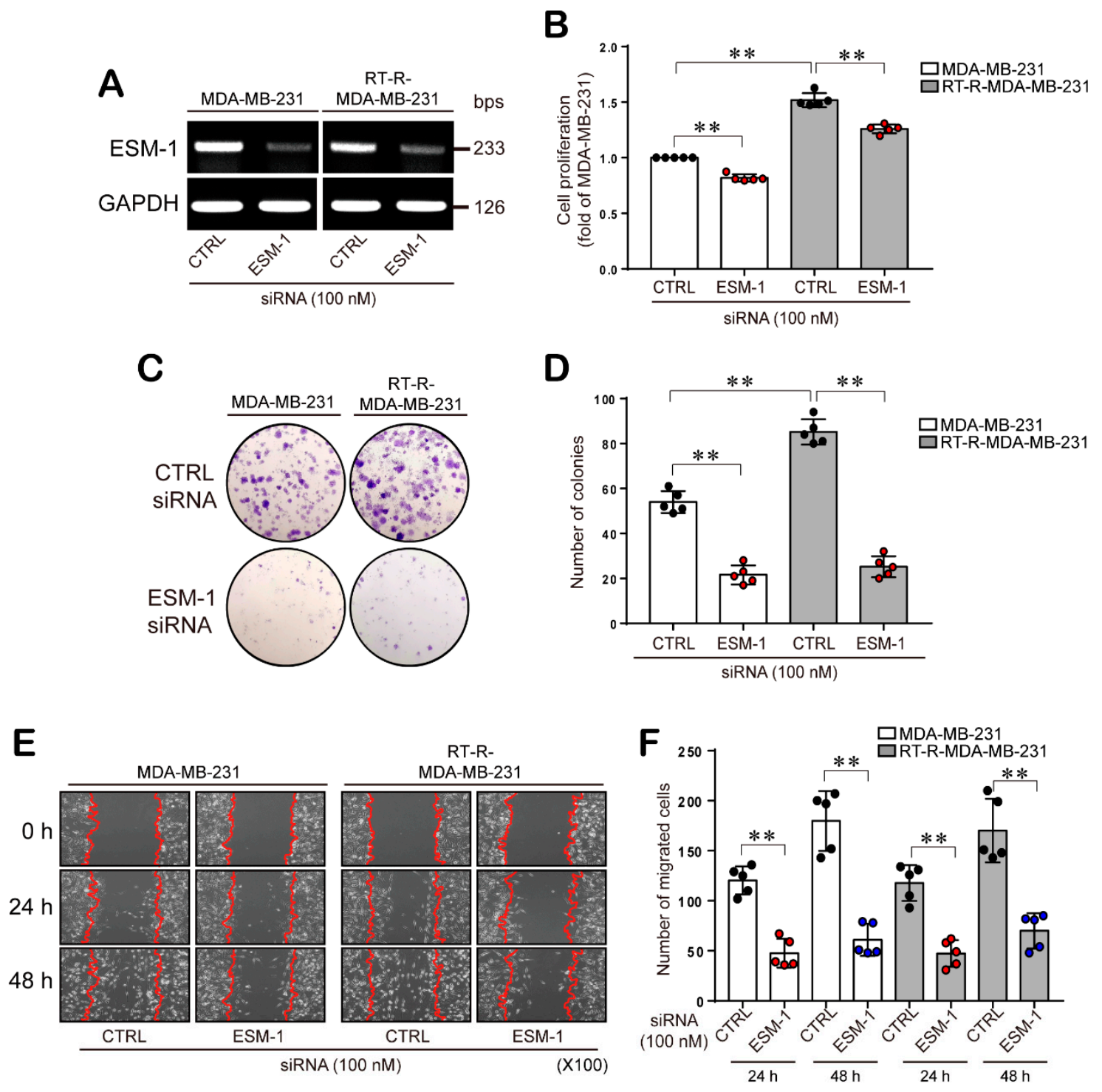

Figure 2. Cont. 

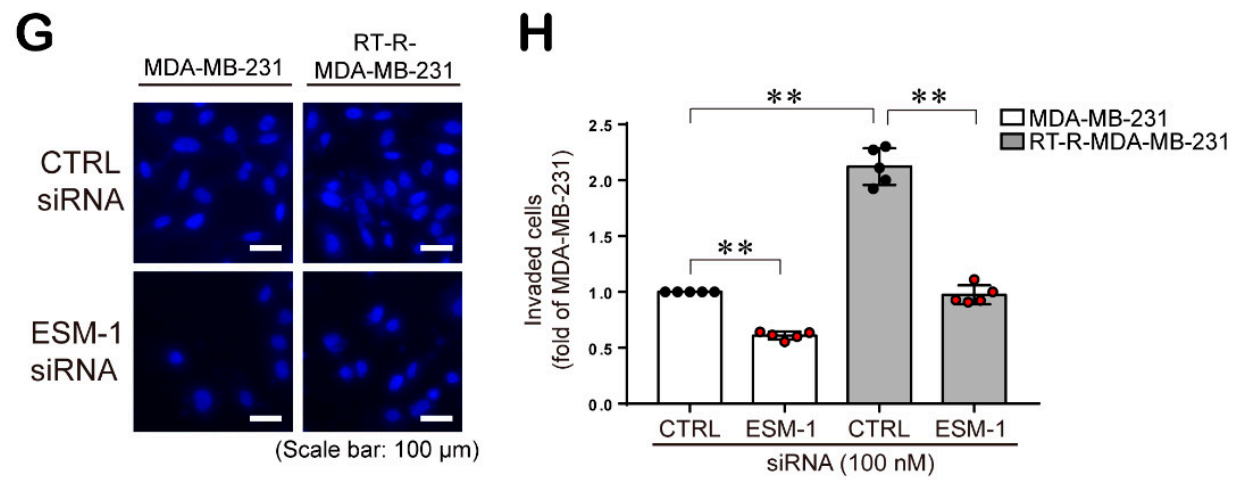

Figure 2. ESM-1 plays an important role in the proliferation, colony formation ability, migration, and invasion of both MDA-MB-231 and RT-R- MDA-MB-231 cells. (A) Cells were transfected with CTRL or ESM siRNA (100 nM) as described in the methods section, and gene silencing efficiency in MDA-MB-231 and RT-R-MDA-MB-231 cells was determined by RT-PCR. The full blot image can be found in Figure S2. (B) CTRL or ESM-1 siRNA-transfected MDA-MB-231 and RT-R-MDA-MB-231 cells were subjected to a cell proliferation assay using CCK-8 reagent as described in the methods section. The data represent the mean \pm SD of five independent experiments. (C,D) CTRL or ESM-1 siRNA-transfected cells $\left(1 \times 10^{3}\right)$ were seeded in 6-well plates, and 10 days later, colonies were stained with Giemsa solution $(0.1 \%)$ (C) and quantified under a light microscope as described in the methods section (D). The data represent the mean \pm SD of five independent experiments. (E) CTRL or ESM-1 siRNA-transfected cells were seeded in 6-well plates, and a wound scratch assay was performed as described in the methods section. (F) The migrated cells were quantified under a microscope 0, 24, and $48 \mathrm{~h}$ after wound scratching. The data represent the mean \pm SD of five independent experiments. $(\mathbf{G}, \mathrm{H})$ CTRL or ESM-1 siRNA-transfected cells were added to EC-Matrigel-coated insert wells and incubated for $16 \mathrm{~h}$ at $37^{\circ} \mathrm{C}$. The invaded cells that had invaded across the membrane were stained with DAPI (G), and five randomly selected fields were counted under a fluorescence microscope $(\mathbf{H})$. The data represent the mean \pm SD of five independent experiments. ${ }^{* *} p<0.01$.

2.3. ESM-1 Plays a Role in Tumorigenesis in MDA-MB-231 and RT-R-MDA-MB-231 Cells through Induction of Adhesion Molecules, Resulting in Adhesion of these Cells to ECs, MMP-9 Activity, and VEGF-A Production

Cell adhesion molecules, such as ICAM-1 and VCAM-1, are involved in cancer growth, migration from primary sites to distant organs, and adhesion to ECs [22,23]. Accordingly, we examined the role of ESM-1 in cell adhesion molecule expression in MDA-MB-231 and RT-R-MDA-MB-231 cells and the subsequent adhesion of these cells to ECs. As shown in Figure 3A-C, ICAM-1 and VCAM-1 protein levels were increased in RT-R-MDA-MB-231 cells compared to MDA-MB-231 cells, and ESM-1 siRNA-transfected RT-R-MDA-MB-231 and MDA-MB-231 cells decreased ICAM-1 and VCAM-1 protein levels. Moreover, 1.7-fold more RT-R-MDA-MB-231 cells than MDA-MB-231 cells adhered to ECs, and the adhesion of ESM-1 siRNA-transfected MDA-MB-231 and RT-R-MDA-MB-231 cells to ECs was significantly decreased compared to that of MDA-MB-231 and RT-R-MDA-MB-231 cells transfected with CTRL siRNA, respectively (Figure 3D-F). During cancer invasion and metastasis, MMPs destroy the surrounding basement membrane, allowing cancer cells to spread to new tissues and inducing the formation of new blood vessels through a process called angiogenesis for tumor growth and persistence. Therefore, we analyzed the effect of ESM-1 on MMP-9 activity and VEGF-A production. As similar with the previous data, RT-R-MDA-MB-231 cells showed increased MMP-9 activity and VEGF-A production compared to that observed in MDA-MB-231 cells, and RT-R-MDA-MB-231 and MDA-MB-231 cells transfected with ESM-1 siRNA exhibited significantly decreased MMP-9 activity (Figure 3G) and VEGF-A production (Figure 3H). 

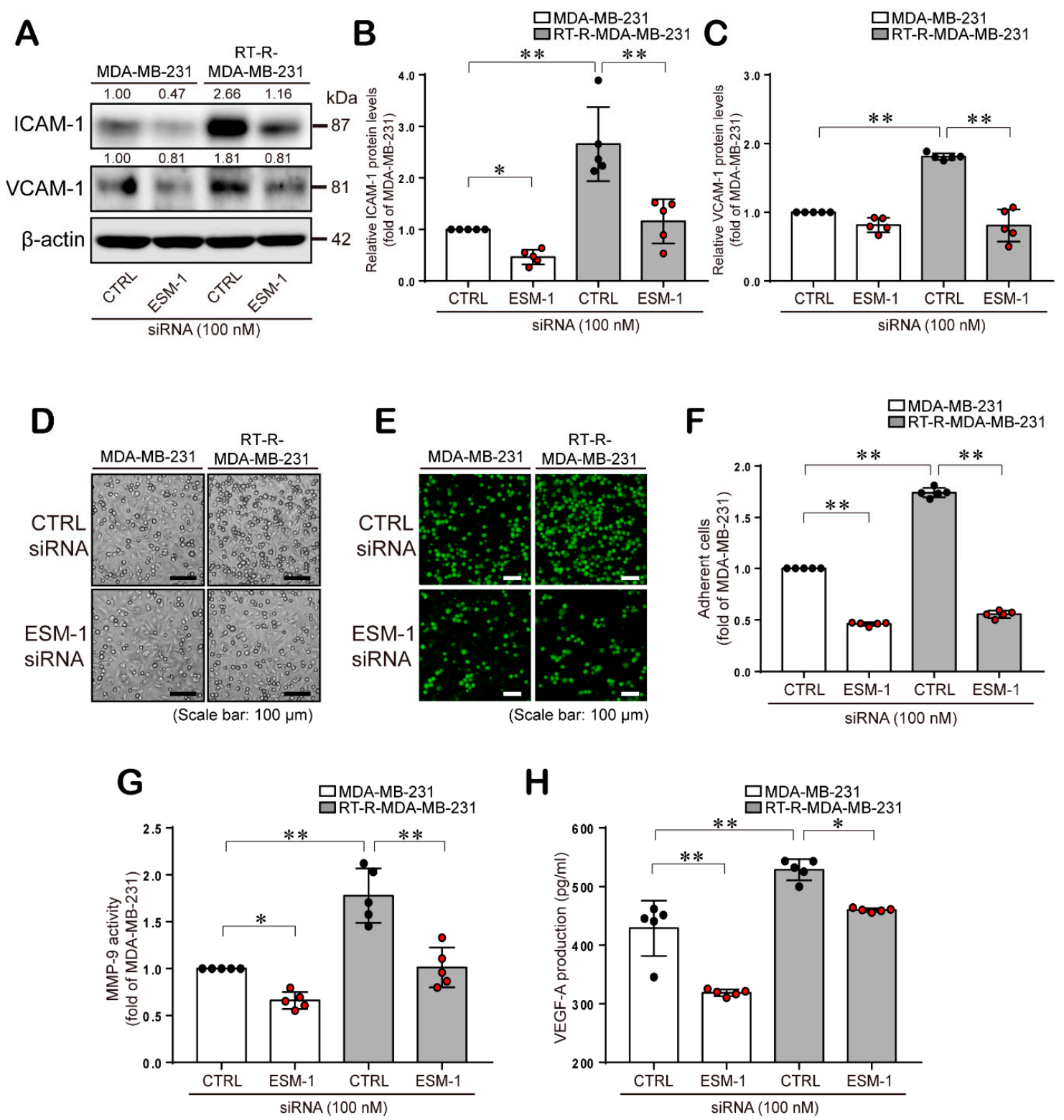

Figure 3. ESM-1 knockdown reduces ICAM-1 and VCAM-1 protein levels, resulting in decreases in the adhesion of cancer cells to ECs, MMP-9 activity, and VEGF-A production in MDA-MB-231 and RT-R-MDA-MB-231 cells. (A) ICAM-1 and VCAM-1 protein levels were analyzed in CTRL or ESM-1 siRNA-transfected MDA-MB-231 and RT-R-MDA-MB-231 cells by western blotting. The full blot image can be found in Figure S3. (B,C) Relative protein levels of ICAM-1 (B) and VC. AM-1 (C) were quantified. The data represent the mean \pm SD of five independent experiments. (D-F) CTRL or ESM-1 siRNA-transfected cells were added to ECs for $30 \mathrm{~min}$, and representative images of the adhesion of cancer cells to ECs are shown using a light microscope (D) and a fluorescence microscope (E). BC cells that had adhered to ECs were quantified in five randomly selected fields under a fluorescence microscope (E). (G,H) Cells were transfected with CTRL or ESM-1 siRNA, and MMP-9 activity (G) and VEGF-A production $(\mathbf{H})$ were detected in conditioned media by zymography and ELISA, respectively. The data represent the mean $\pm \mathrm{SD}$ of five independent experiments. ${ }^{*} p<0.05,{ }^{* *} p<0.01$.

2.4. ESM-1-Overexpressing RT-R-MDA-MB-231 Cells Increase ERK1/2, PKC, and PDK1 Activation and then Transcription Factor Hypoxia-Inducible Factor-1 $\alpha$ (HIF-1 $\alpha)$ Induction and NF- $\kappa B$ and STAT-3 Activation

Then, we investigated the effect of ESM1 on the intracellular signaling molecules, which are involved in cell survival, cell migration, and metastasis. We found that ERK1/2, PKC, and 
PDK1 phosphorylations were highly induced in RT-R-MDA-MB-231 cells than in MDA-MB-231 cells. Phosphorylated ERK1/2, PKC, and PDK1 protein levels were significantly suppressed in both MDA-MB-231 and RT-R-MDA-MB-231 cells transfected with ESM1 siRNA (Figure 4A-F). Based on the reports, these ERK1/2, PKC, and PDK1 pathways potentiate the activation of HIF- $1 \alpha$, NF- $k B$, and STAT-3, and these transcription factors are well known to be involved in inflammatory responses to promote cancer development and growth through the transcriptional regulation of various inflammatory genes, such as adhesion molecules, MMPs, and VEGF [24-30]. Thus, we wanted to determine the effect of ESM-1 overexpression on these transcription factors in RT-R-MDA-MB-231 cells. Western blot analysis revealed that compared with MDA-MB-231 cells, RT-R-MDA-MB-231 cells overexpressing ESM-1 exhibited enhanced HIF- $1 \alpha$ protein expression and NF-KB and STAT-3 activation and that ESM-1 knockdown induced by siRNA reduced HIF- $1 \alpha$ protein expression and NF- $\mathrm{kB}$ and STAT- 3 activation in RT-R-MDA-MB-231 and MDA-MB-231 cells (Figure 5A-F).
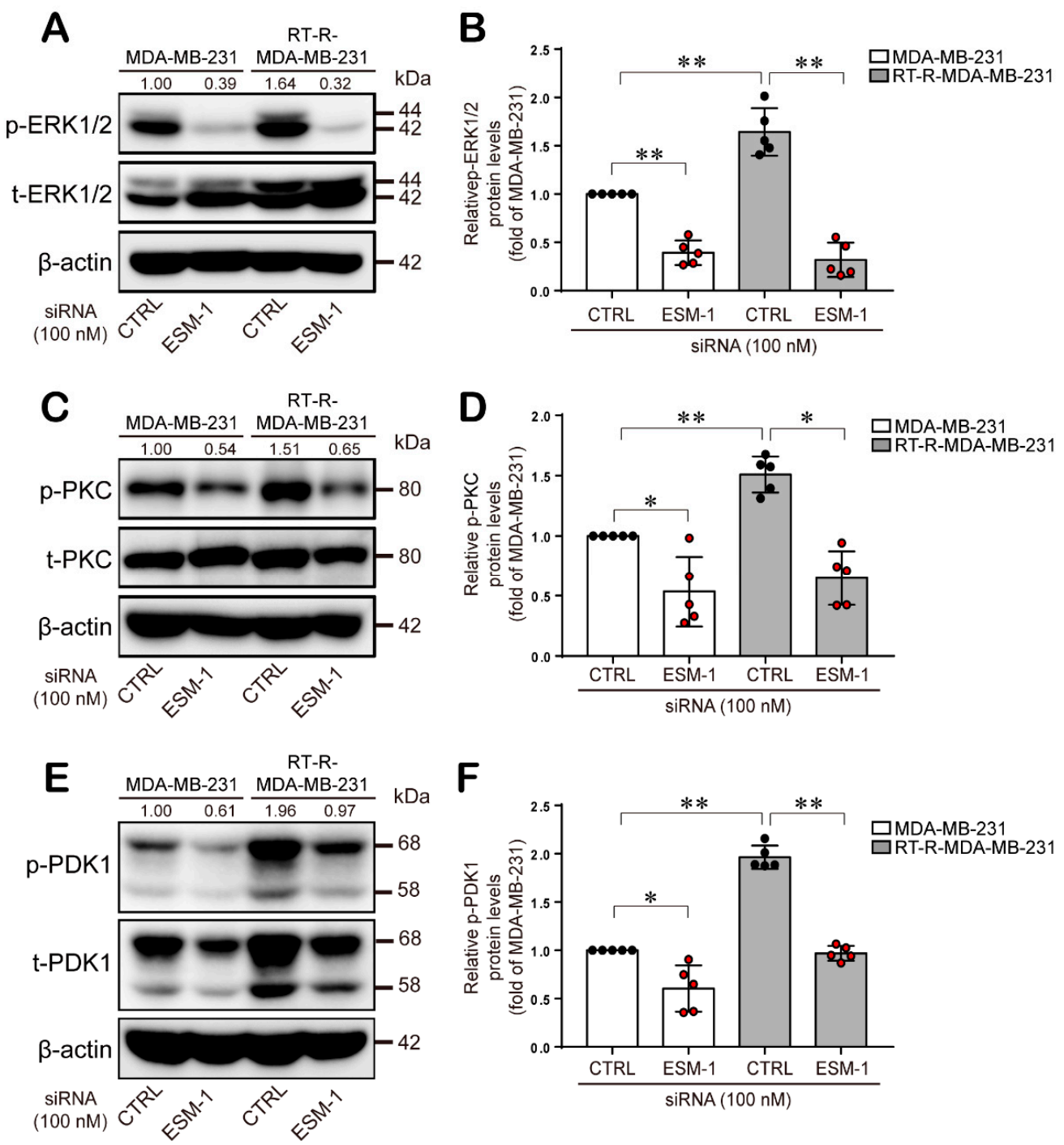

Figure 4. ERK1/2, PKC, and PDK1 phosphorylation are enhanced in RT-R-MDA-MB-231 cells compared to MDA-MB-231 cells and are suppressed by knockdown of ESM-1. Cell lysates were obtained from the CTRL- or ESM-1 siRNA-transfected cells, and western blotting was performed to detect the expressions of phospho-ERK1/2/ERK1/2 (A), phospho-PKC/PKC (C), and phospho-PDK1/PDK1 (E). Band densities were quantified, and the relative protein levels are presented as the mean $\pm \mathrm{SD}$ of five independent experiments $(\mathbf{B}, \mathbf{D}, \mathbf{F}) .{ }^{*} p<0.05,{ }^{* *} p<0.01$. The full blot images can be found in Figure S4. 
A
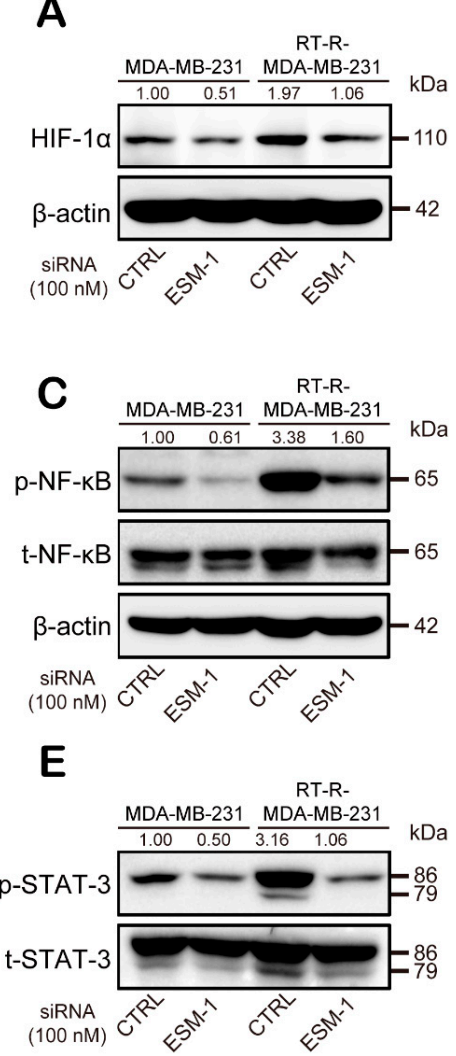

B
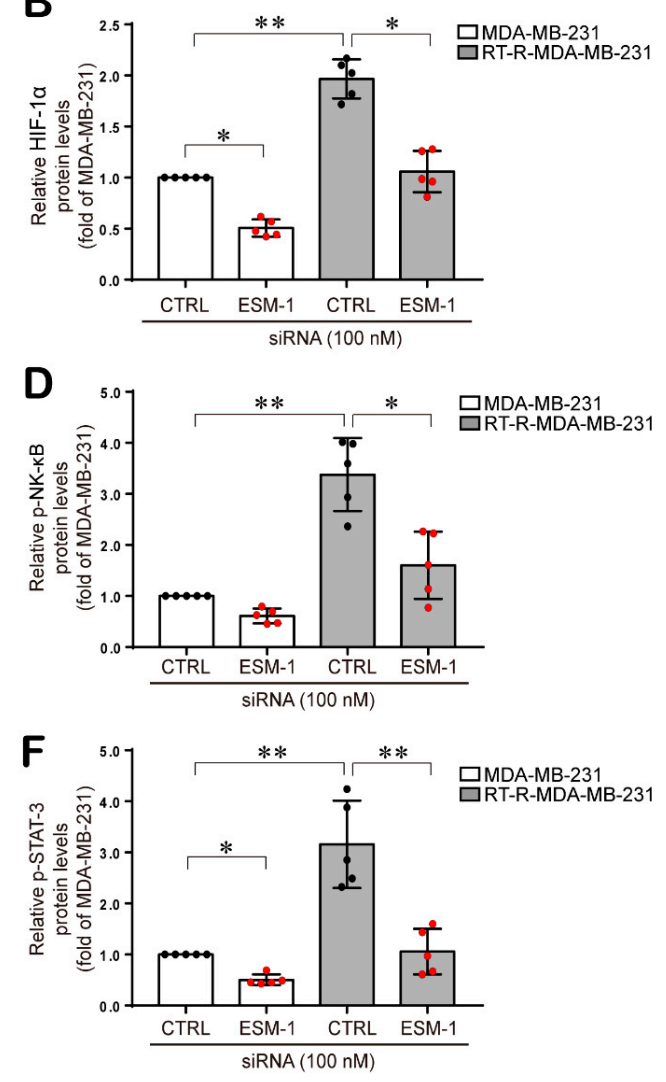

Figure 5. HIF- $1 \alpha$ induction and NF- $\kappa B$ and STAT-3 phosphorylation are increased in RT-R-MDA-MB-231 cells compared to MDA-MB-231 cells and are downregulated by ESM-1 knockdown. Cell lysates were obtained from the CTRL- or ESM-1 siRNA-transfected cells, and western blotting was performed to detect HIF-1 $\alpha$ (A), phospho-NF- $\mathrm{kB} / \mathrm{NF}-\mathrm{kB}(\mathbf{C})$, and phospho-STAT-3/STAT-3 expression (E). Band densities were quantified, and the relative protein levels are presented as the mean $\pm \mathrm{SD}$ of five independent experiments $(\mathbf{B}, \mathbf{D}, \mathbf{F}) .{ }^{*} p<0.05,{ }^{* *} p<0.01$. The full blot images can be found in Figure S5.

\subsection{ESM-1 Overexpression Increases Tumor Growth and Metastasis in an In Vivo Mouse Model}

Finally, we confirmed the role of ESM-1 in tumorigenesis in an in vivo mouse model. We divided athymic nude mice into four groups and subcutaneously injected them with empty plasmid vector-transfected 4T1 (4T1) cells, empty plasmid vector-transfected RT-R-4T1 (RT-R-4T1) cells, ESM-1 plasmid vector-transfected 4T1 (4T1-ESM-1) cells, or ESM-1 plasmid vector-transfected RT-R-4T1 (RT-R-4T1-ESM-1) cells (Figure 6A). Tumor volume and body weight were measured every 3 days for 24 days. The tumor volume of mice injected with 4T1-ESM-1 cells and RT-R-4T1-ESM-1 cells was significantly increased from the 14th day after injection (Figure 6B). In addition, we found that mice injected with RT-R-4T1-ESM-1 cells presented the greater increase in tumor volume (Figure 6C,D), even though the body weights of the four groups were not significantly different during tumor development (Figure 6E). Interestingly, on the day that the mice were sacrificed, lung metastasis examination showed that RT-R-4T1 cell-injected mice showed an increased number of lung metastases compared to that exhibited by $4 \mathrm{~T} 1$ cell-injected mice, and this effect was more prominent in mice injected with 4T1-ESM-1 cells and RT-R-4T1-ESM-1 cells; 4T1-ESM-1 cell-injected and RT-R-4T1-ESM-1 cell-injected mice showed a significant increase in lung metastasis compared to that of 4T1 cell- and RT-R-4T1 cell-injected mice, respectively (Figure 6F). The tumor angiogenic marker VEGF-A was significantly increased in mice injected with 4T1-ESM-1 and RT-R-4T1-ESM-1 cells (Figure 6G). Immunohistochemistry (IHC) staining showed that mice injected with ESM-1-overexpressing 4T1 and RT-R-4T1 cells exhibited significant increases in tumorigenesis-related molecules (ICAM-1, VCAM-1, MMP-9, HIF- $1 \alpha$, phospho-NF- $\mathrm{B}$, and phospho-STAT-3) (Figure 6H). 

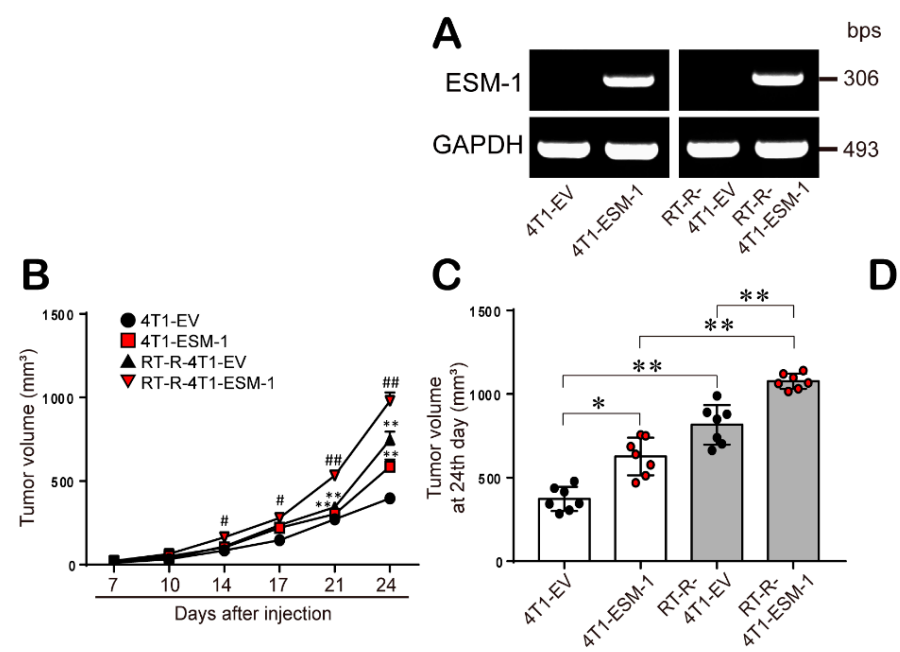

D
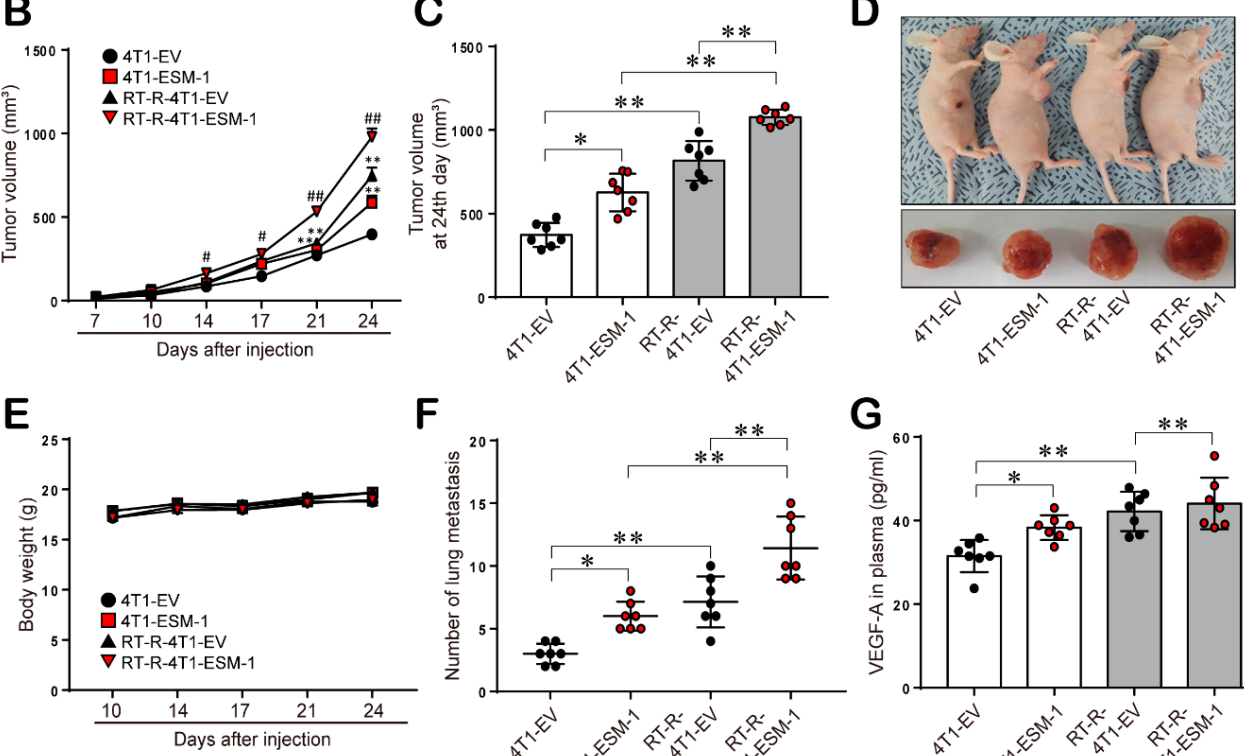

$\mathbf{F}$

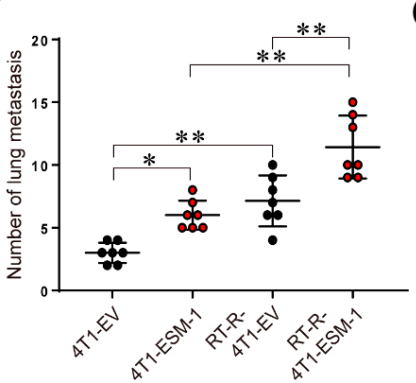

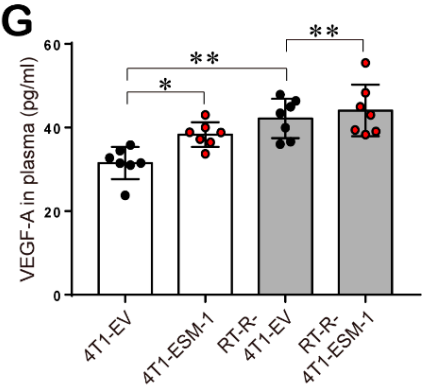

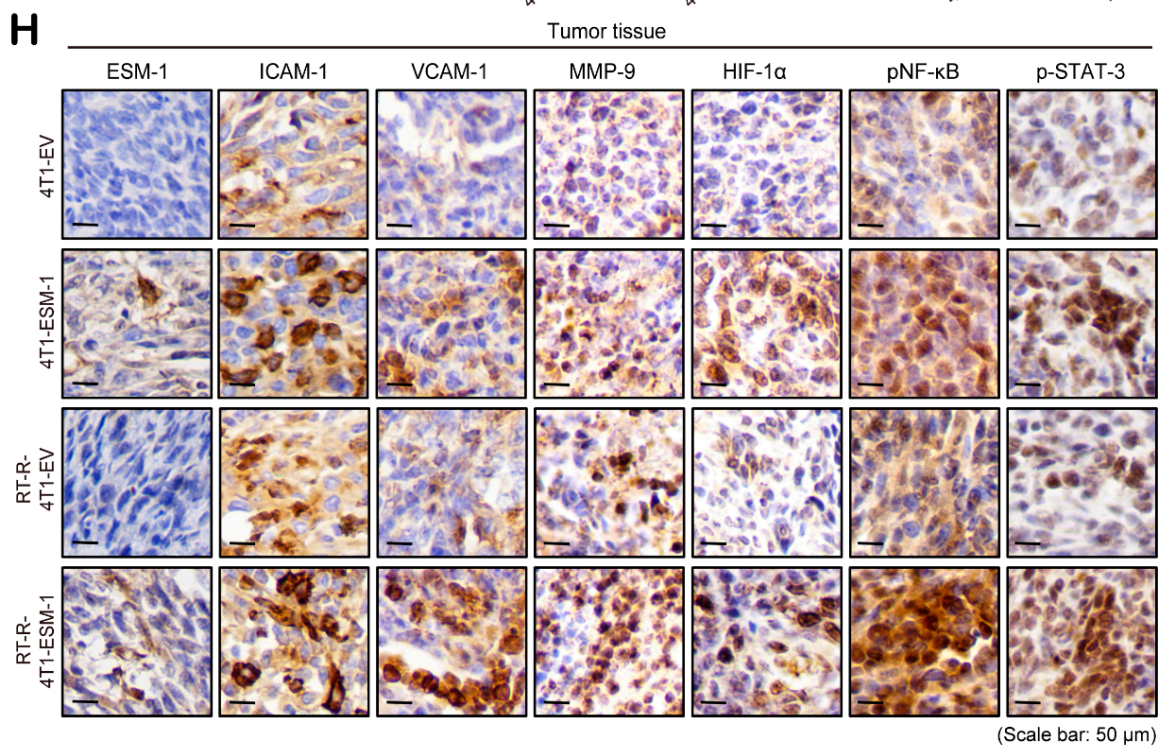

Figure 6. ESM-1 overexpression increases tumor growth and metastasis in an in vivo mouse model. (A) 4T1 and RT-R-4T1 mouse breast cancer (BC) cells were stably transfected with expression plasmid vectors encoding ESM-1 (4T1-ESM-1 and RT-R-4T1-ESM-1 cells) or with an empty vector (4T1-EV and RT-R-4T1-EV cells) as described in the methods section. The full blot image can be found in Figure S6. (B-H) Athymic nude mice were divided into four groups and injected subcutaneously with 4T1-EV cells ( $4 \mathrm{~T} 1 ; n=7)$, RT-R-4T1-EV cells $(n=7), 4 \mathrm{~T} 1$-ESM-1 cells $(n=7)$, or RT-R-4T1-ESM-1 cells $(n=7)$ $\left(5 \times 10^{4}\right.$ cells $/ 50 \mu \mathrm{L}$ of serum-free medium). The mice were sacrificed on the 24 th day, and the tumors and lung tissues were extracted. Tumor volume (B-D) and body weight (E) were measured every three days during tumor development. The incidence of lung metastasis (F) was examined after sacrifice. (G) VEGF-A was detected in the plasma by ELISA. The data represent the mean \pm SD. ${ }^{*} p<0.05$, $* * p<0.01$. (H) Tumor tissue sections were stained with anti-ESM-1, ICAM-1, VCAM-1, MMP-9, HIF-1 $\alpha$, phospho-NF-kB, and phospho-STAT-3 antibodies. 


\section{Discussion}

ESM-1 is a secreted proteoglycan dermatan produced by ECs, and as mentioned in the introduction, a high level of ESM-1 secretion has been found in various cancers. In addition, recent reports have suggested that ESM-1 is a biomarker of TNBC [19] and colorectal cancer [31,32]. However, the role of ESM-1 in tumorigenesis in BC, especially RT-R TNBC, is not well known. RT is a main treatment for breast cancer; however, once it acquires radioresistance, it becomes hard to overcome $\mathrm{BC}$. Therefore, in the previous study, we established RT-R-BC cells and studied the changed properties of RT-R-BC cells $[5,6]$. As mentioned in the introduction, RT-R-MDA-MB-231 cells showed the most radio- and chemo-resistance of tested other RT-R nonTNBC cells and showed increased metastatic properties including increased invasion. In another trial to overcome radioresistance in $\mathrm{BC}$, in this study, we analyzed gene expression levels between MDA-MB-231 cells, a highly metastatic TNBC, and RT-R-MDA-MB-231 cells derived from MDA-MB-231 cells. Interestingly, as shown in Table 1, we found that the ESM-1 was most upregulated in RT-R-MDA-MB-231 cells, compared to MDA-MB-231 cells. Accordingly, we investigated the role of ESM-1 overexpression in the increased tumorigenesis of RT-R-MDA-MB-231 cells. The results of our study showed that at both the mRNA and protein levels, ESM-1 expression was higher in RT-R-MDA-MB-231 cells than in MDA-MB-231 (Figure 1A-C). These results suggest that the overexpression of ESM-1 in RT-R-MDA-MB-231 cells may be the reason why they are more tumorigenic than MDA-MB-231 cells. Actually, in Figure 2A-H, RT-R-MDA-MB-231 cells showed significantly increased proliferation, colony formation ability, migration, and invasion compared to MDA-MB-231 cells, and these effects were significantly reduced by knocking down of ESM-1. A report by Sagara et al. [19] also supports our results; ESM-1 was overexpressed in MDA-MB-231 cells with a brain metastatic phenotype (MDA-MB-231 BR), which are more malignant than MDA-MB-231. The results from Sagara et al. showed that ESM1 gene expression in MDA-MB-231 BR was almost 760-fold higher than that of MDA-MB-231, which is twice as high as our result (320-fold in RT-R-MDA-MB-231 vs. MDA-MB-231), and ESM1 protein level observed in Sagara et al. was also higher than our result. From these results, we could assume that MDA-MB-231 BR might be more aggressive than RT-R-MDA-MB-231. However, the most important common finding is that ESM1 increased in malignant $\mathrm{BC}$ cells and play an important role in tumorigenesis of $\mathrm{BC}$.

Compared to normal ECs, BC cells highly express the cell adhesion molecules ICAM-1 and VCAM-1. Our previous study also showed that ICAM-1 and VCAM-1 are involved in tumor growth and migration and the adhesion of cancer cells to other organs [33]. Therefore, in this study, we also examined the role of ESM-1 in cell adhesion molecule expression, the adhesion of cancer cells to ECs, and metastasis-related factors such as MMP-9 and VEGF-A. As expected, compared to MDA-MB-231 cells, RT-R-MDA-MB-231 cells showed increased expression levels of ICAM-1 and VCAM-1 and therefore increased adhesion to ECs, which were significantly inhibited by ESM-1 knockdown (Figure 3A-F). In addition, MMP-9 activity and VEGF-A production were significantly increased in RT-R-MDA-MB-231 cells compared to MDA-MB-231 cells and were significantly reduced in ESM-1 siRNA-transfected RT-R-MDA-MB-231 and MDA-MB-231 cells (Figure 3G,H). These results suggest that the elevated expression of ESM-1 in RT-R-MDA-MB-231 cells may be the reason why RT-R-MDA-MB-231 cells are more tumorigenic than MDA-MB-231 cells.

It has been reported that several signaling molecules affect the tumorigenesis of BC cells. PDK1, which is downstream of phosphoinositide 3-kinase (PI3K) and activated by hormones and growth factors, activates several kinase pathways, including the AKT and PKC pathways, which are involved in the regulation of cell growth, proliferation, survival, and metabolism [34,35]. PDK1 is overexpressed in human BC models, and PDK1 knockdown abolishes tumorigenesis in xenografts [36]. PKCs are activated by the PI3K and PDK1 pathways and then regulate several genes involved in tumor progression, metastasis, and tumorigenesis [37], resulting in the promotion of tumor growth and metastasis [38]. Moreover, PKC increases migration and invasion through the ERK/AP-1 pathway and the production of MMP-9 [39]. The ERK pathway is also involved in tumorigenesis by promoting cell proliferation, survival, and angiogenesis, resulting in decreased life expectancy of TNBC patients [40]. 
Activation of the ERK pathway potentiates the activation of HIF- $1 \alpha, \mathrm{NF}-\mathrm{kB}$, and STAT-3, and these transcription factors are well known to be involved in the tumor growth and progression through the transcriptional regulation of various inflammatory genes, such as adhesion molecules, MMPs, and VEGF [26-40]. Accordingly, we investigated the effect of ESM-1 on the activation of these intracellular signaling molecules and transcription factors. In our study, RT-R-MDA-MB-231 cells exhibited the increased activation of PDK1, PKC, and ERK1/2 pathways, and moreover, higher expression of HIF- $1 \alpha$ and phosphorylation of NF-KB and STAT-3 than MDA-MB-231 cells. However, the expression or the activation of these molecules was reduced in ESM-1 siRNA-transfected RT-R-MDA-MB-231 and MDA-MB-231 (Figures 4 and 5). Interestingly, ESM-1 siRNA-transfected RT-R-MDA-MB-231 cells showed a more dramatic decrease in the expression and activation of these molecules than MDA-MB-231 cells. These results suggest that ESM-1 plays an important role in tumorigenesis in MDA-MB-231 cells and especially RT-R-MDA-MB-231 cells through regulation of these transcription factors.

Finally, we confirmed the role of ESM-1 in tumorigenesis in a mouse xenograft model by subcutaneous injecting normal or ESM-1 expressing 4T1 or RT-R-4T1 murine breast cancer cells into athymic nude mice. In our previous study, mice that were injected with MDA-MB-231 and RT-R-MDA-MB-231 developed tumor mass within a few days but decreased tumor mass as a few days went on, possibly due to the immune barrier. Even though RT-R-MDA-MB-231 increased tumor growth again in the late phase, we failed to observe the successful metastasis to other organs. 4T1 cell is an animal model for stage IV human BC and can mimic the biology of MDA-MB-231, which are highly metastatic BC cells. For this reason, we made a mice xenograft model using 4T1 cells and RT-R-4T1 cells to investigate the role of ESM-1 on tumorigenesis including metastasis in vivo. Furthermore, 4T1 cells do not express ESM-1, so it is good model to study the role of ESM-1 after ESM-1 transfection. Thus, we generated ESM-1-overexpressing 4T1 and RT-R-4T1 cells (Figure 6A). Consistent with the in vitro results, mice injected with ESM-1-overexpressing $4 \mathrm{~T} 1$ cells exhibited significant increases in tumor volume (Figure 6B-D), lung metastasis (Figure 6F), metastasis-related molecules (VEGF, MMP-9, ICAM-1, and VCAM-1), and transcription factors (HIF- $1 \alpha$, phospho-NF- $\mathrm{BB}$, and phospho-STAT-3) (Figure 6H). This phenomenon was more prominent in the mice injected with ESM-1-overexpressing RT-R-4T1 cells.

\section{Materials and Methods}

\subsection{Cell Culture}

Human BC cell lines, MDA-MB-231, were obtained from the Korea Cell Line Bank (Seoul, Korea), and the mouse BC cell line, 4T1, and human umbilical vascular endothelial cell line, EA.hy 926, were provided by the American Type Culture Collection (ATCC, Manassas, VA, USA). All cancer cell lines were cultured in RPMI-1640, and EA.hy 926 cells were grown in DMEM. Both media were supplemented with $10 \%$ fetal bovine serum (FBS), $100 \mathrm{IU} / \mathrm{mL}$ penicillin, and $10 \mu \mathrm{g} / \mathrm{mL}$ streptomycin (all from HyClone; GE Healthcare Life Sciences, Logan, UT, USA). The cells were incubated at $37^{\circ} \mathrm{C}$ in an incubator containing $5 \% \mathrm{CO}_{2}$.

\subsection{Establishment of RT-R-Breast Cancer Cells}

RT-R-BC cells (RT-R-MDA-MB-231 cells and RT-R-4T1 cells) were generated from MDA-MB-231 and $4 \mathrm{~T} 1$ cells as previously described [5]. Briefly, cells were irradiated regularly 25 times at $2 \mathrm{~Gy}$ (total $50 \mathrm{~Gy})$, which is a commonly used clinical regimen for the radiotherapy of breast cancer patient, by using a 6-MV photon beam produced by a linear accelerator (Clinac 21EX, Varian Medical Systems, Inc., Palo Alto, CA, USA). After irradiation, cells were grown until they reached approximately $90 \%$ confluence, and then, they were trypsinized and subcultured into new flasks. They were irradiated again when the cells reached proximately $70 \%$ confluence, which took about 1 week after subculture. The fractionated irradiations were continued until the total dose reached $50 \mathrm{~Gy}$, which totally took about 6 months. 


\subsection{Gene Expression Array Analysis}

Total RNA was extracted using TRIzol reagent (Invitrogen, Carlsbad, CA, USA), based on a protocol of the manufacturer, from MDA-MB-231 and RT-R-MDA-MB-231 cells. Then, gene expression profiling was performed by using the QuantiSeq 3' mRNA-Seq Service (Ebiogen, Seoul, Korea).

\subsection{Gene Silencing with siRNA}

Cells were transfected with $100 \mathrm{nM}$ negative CTRL siRNA or ESM-1 siRNA (Bioneer, Daejeon, Korea) using Turbofect ${ }^{\circledR}$ (Thermo Fisher Scientific, Rockford, IL, USA). The siRNA sequences were as follows: CTRL siRNA forward: 5'-CCUACGCCACCAAUUUCGU-3'; CTRL siRNA reverse: 5'-ACGAA AUUGGUGGCGUAGG-3'; ESM-1 siRNA forward: 5'-CU GAA CAC UUG UAU GUG UU-3'; and ESM-1 siRNA reverse: 5'-AA CAC AUA CAA GYG UUC AG-3'. The cells were incubated in complete medium containing transfection reagent for $24 \mathrm{~h}$, and then the transfection medium was replaced with fresh serum-free medium for starvation. Reverse transcription-polymerase chain reaction (RT-PCR) was performed to determine the efficiency of the gene silencing.

\subsection{RT-PCR}

Extracted total RNA was applied to RT-PCR using TOPscript One-step RT-PCR Drymix (Enzynomics, Daejeon, Korea) according to the manufacturer's instructions. The sequences of the primers used were as follows: hESM-1 forward: 5'-GC CCT TCC TTG GTA GGT AGC-3' and reverse: 5'-TG TTT CCT ATG CCC CAG AAC-3'; mESM-1 forward: 5'-ACT CCT GGT ACC TCT GCA CC-3' and reverse: 5' - CAT TCC ATC CCG AAG GTG CC-3'; hGAPDH forward: 5' - TCA ACA GCG ACA CCC ACT CC-3' and reverse: 5'-TGA GGT CCA CCC TGT TG-3'; and mGAPDH forward: 5'-GCT GAG TAC GTG GAG-3' and reverse: 5'-CAT ACT TGG CAG GTT TCT-3'. Thirty cycles of amplification were performed under the following conditions: melting at $95^{\circ} \mathrm{C}$ for $30 \mathrm{~s}$, annealing at $57.5^{\circ} \mathrm{C}$ or $60^{\circ} \mathrm{C}$ for hESM- 1 or mESM-1, respectively, for $30 \mathrm{~s}$, and extension at $72{ }^{\circ} \mathrm{C}$ for $30 \mathrm{~s}$.

\subsection{Cell Proliferation Assay}

Cell proliferation was analyzed by the CCK-8 assay. CTRL siRNA or ESM-1 siRNA-transfected cells were seeded in 96-well plates (Thermo Fisher Scientific) and incubated for $24 \mathrm{~h}$. Then, cells were added with $10 \mu \mathrm{L}$ CCK-8 reagent and incubated for an additional $30 \mathrm{~min}$. The optical density of each well was measured at a wavelength of $450 \mathrm{~nm}$ using a microplate reader (Tecan, Männedorf, Switzerland).

\subsection{Colony Formation Assay}

Colony formation assays were performed as described previously [6]. Briefly, CTRL siRNA or ESM-1 siRNA-transfected MDA-MB-231 and RT-R-MDA-MB-231 cells $\left(1 \times 10^{3}\right.$ cells/wells $)$ were seeded in 6-well plates and incubated for 10 days. During incubation, the medium was changed every 2-3 days. After 10 days, the medium was discarded, and each well was carefully washed with PBS. The colonies were fixed in $100 \%$ methanol for $10 \mathrm{~min}$ at room temperature and then stained with $0.1 \%$ Giemsa staining solution, the number of visible colonies was counted, and the migrated cells were counted.

\subsection{Wound Healing Assay}

CTRL siRNA or ESM-1 siRNA-transfected MDA-MB-231 and RT-R-MDA-MB-231 cells $\left(2 \times 10^{5}\right.$ cells/well $)$ were cultured in 24 -well plates and scratched with a sterile pipette tip. The cells were washed with PBS and incubated at $37^{\circ} \mathrm{C}$ in fresh medium for $24 \mathrm{~h}$ or $48 \mathrm{~h}$. Images were taken 0 , 24 , and $48 \mathrm{~h}$ after scratching using an Olympus photomicroscope. Cells migrated into scratched area were counted. 


\subsection{Adhesion Assay}

ECs were seeded in 6-well plates and cultured until about 90\% confluence. CTRL siRNA or ESM-1 siRNA-transfected MDA-MB-231 and RT-R-MDA-MB-231 cells $\left(7.5 \times 10^{5}\right.$ cells/mL, $2 \mathrm{~mL} /$ well $)$ were stained with $10 \mu \mathrm{g} / \mathrm{mL}$ of the fluorescent dye BCECF-AM (Boehringer, Mannheim, Germany) at $37^{\circ} \mathrm{C}$ for $30 \mathrm{~min}$, and then fluorescence labeled cells were pelleted, resuspended, and added on ECs. After $30 \mathrm{~min}$ incubation at $37^{\circ} \mathrm{C}$, the cell suspensions were removed, and the ECs were washed three times with $1 \times$ PBS. The ECs were then visualized under a light microscope $(200 \times$ magnification) and fluorescent cancer cells were visualized using a fluorescence microscope (Eclipse Ti-U, Nikon, Tokyo, Japan). The number of cancer cells that adhered to ECs was quantified.

\subsection{Matrigel Invasion Assay}

Invasion assays were performed according to Jin et al. [33] with minor modifications, as described below. The upper chambers of inserts were coated with $100 \mu \mathrm{L}$ of Matrigel $(1 \mathrm{mg} / \mathrm{mL}$; BD Biosciences, Franklin Lakes, NJ, USA), and ECs $\left(2 \times 10^{5}\right.$ cells) were added to the Matrigel-coated insert wells. CTRL or ESM-1 siRNA-transfected MDA-MB-231 or RT-R-MDA-MB- 231 cells $\left(2 \times 10^{5}\right.$ cells/insert well) in serum-free medium were added to the upper chambers and incubated for $24 \mathrm{~h}$. Then, the noninvaded cells that remained on the upper surface of the insert membranes were removed by scrubbing. The cells that had invaded across the insert well membrane were stained with 4',6-diamidine-2'-phenylindole dihydrochloride (DAPI, Sigma-Aldrich, St. Louis, MO, USA) and were counted in five randomly selected fields under a fluorescence microscope (Eclipse Ti-U, Nikon).

\subsection{Gelatin Zymography}

Cells $\left(1 \times 10^{6}\right.$ cells $)$ were seeded in $100 \mathrm{~mm}$ cell culture dishes and cultured overnight $(16 \mathrm{~h})$. Then, the cells were transfected with CTRL or ESM- 1 siRNA for $24 \mathrm{~h}$ at $37^{\circ} \mathrm{C}$, and the same volume of each conditioned medium was then concentrated 20-fold using protein concentrators (9K MWCO; Thermo Fisher Scientific). The concentrated media were mixed with $2 \times$ loading dye and subjected to electrophoresis on $8 \%$ sodium dodecyl sulfate-polyacrylamide gel electrophoresis (SDS-PAGE) gels containing $1 \mathrm{mg} / \mathrm{mL}$ gelatin. The gels were stained with Coomassie blue solution $(0.2 \%$ Coomassie brilliant blue R, $50 \%$ methanol, and 10\% acetic acid) for $30 \mathrm{~min}$ and destained with destaining buffer (50\% methanol and $10 \%$ acetic acid). The enzyme-digested regions that represent MMP-9 activity were identified as white bands on a blue background.

\subsection{Quantitative VEGF-A Immunoassay}

The concentration of VEGF-A in conditioned medium from CTRL or ESM-1 siRNA-transfected MDA-MB-231 and RT-R-MDA-MB-231 cells or the plasma from mice injected with 4T1-empty vector (EV), 4T1-ESM-1, RT-R-4T1-EV, or RT-R-4T1-ESM-1 cells was determined using a VEGF-A enzyme-linked immunosorbent assay kit (R\&D Systems, Minneapolis, MN, USA) according to the manufacturer's instructions.

\subsection{Quantification of ESM-1 Secretion}

Cells $\left(1 \times 10^{5}\right.$ cells $)$ were seeded in 6-well plates and then incubated for $72 \mathrm{~h}$ in complete medium at $37^{\circ} \mathrm{C}$. Then, the levels of ESM-1 secreted into cell culture medium were analyzed by using a human ESM-1 quantikine ELISA kit (Novus Biologicals, Centennial, CO, USA) according to the manufacturer's protocol. All assays were performed in triplicate. The optical density of each well was measured at $450 \mathrm{~nm}$ using a microplate reader (Tecan).

\subsection{Western Blot Analysis}

Western blot analysis was performed as described previously [33] with minor modifications. Briefly, aliquots of 30-60 $\mu \mathrm{g}$ of protein were subjected to 8-12\% SDS-PAGE and transferred onto 
Hybond- $\mathrm{P}^{+}$polyvinylidene difluoride membranes (Amersham, Buckinghamshire, UK). The membranes were incubated with the following primary antibodies: anti-ICAM-1 (ab225884, 1:1000, Abcam, Cambridge, UK), anti-VCAM-1 (ab106778, 1:1000, Abcam), anti-phospho-ERK (sc-7383, 1:1000, Santa Cruz Biotechnology), anti-total-ERK (sc-94 1:1000, Santa Cruz Biotechnology), anti-phospho-PKC (9375S, 1:1000, Cell Signaling Technology, Danvers, MA, USA), anti-PKC (sc-10800, 1:1000, Santa Cruz Biotechnology), anti-phospho-PDK1 (3061S, 1:1000, Cell Signaling Technology), anti-PDK1 (3062S, 1:1000, Cell Signaling Technology), anti-phospho-STAT-3 (9131S, 1:1000, Cell Signaling Technology, anti-STAT-3 (4904S, 1:1000, Cell Signaling Technology), anti-HIF-1 $\alpha$ (ab2185, 1:1000, Abcam), anti-phospho-NF-kB (8242S, 1:1000, Cell Signaling Technology), anti-NF-kB (8242S 1:1000, Cell Signaling Technology), and anti- $\beta$-actin (A2066, 1:2000, Sigma-Aldrich, St. Louis, MO, USA). The bound antibodies were detected with horseradish peroxidase-conjugated secondary antibodies and an ECL western blotting detection reagent (Bio-Rad, Hercules, CA, USA).

\subsection{ESM-1 Overexpression in $4 T 1$ and $R T-R-4 T 1$ cells}

4T1 and RT-R-4T1 murine BC were stably transfected with an ESM-1 plasmid vector (PCMV6-kan/ Neo, OriGene Technologies, Inc., Rockville, MD, USA), which contained a neomycin resistance gene for the selection of cells stably expressing ESM-1, in serum-free medium using Lipofectamine 3000 (Thermo Fisher Scientific). Following $4 \mathrm{~h}$ of incubation at $37^{\circ} \mathrm{C}$, the transfection medium was replaced with fresh medium containing $500 \mu \mathrm{g} / \mathrm{mL}$ neomycin (G-418; Sigma-Aldrich). The culture medium containing neomycin was changed every 2-3 days. Thirty days after transfection, ESM-1 overexpression was confirmed from the total RNA extracted from the cells by RT-PCR.

\subsection{Animal Experiments}

Athymic nude mice (6-week-old females) were purchased from OrientBio (Gyeonggi-do, Korea) and maintained under the following constant ambient conditions: $22{ }^{\circ} \mathrm{C}$ to $26^{\circ} \mathrm{C} ; 40 \%$ to $60 \%$ humidity, $12 \mathrm{~h} \mathrm{light/dark} \mathrm{cycle;} \mathrm{and} \mathrm{free} \mathrm{access} \mathrm{to} \mathrm{sterilized} \mathrm{food} \mathrm{and} \mathrm{water.} \mathrm{Mice} \mathrm{were} \mathrm{divided} \mathrm{into} 4$ groups $(n=7 /$ each group) and injected subcutaneously with $5 \times 10^{4}$ cells/50 $\mu$ L of 4T1-EV, RT-R-4T1-EV, 4T1-ESM-1, or RT-R-4T1-ESM-1 cells. Body weight and tumor volume were measured twice a week starting from the 7 th day after injection. The mice were sacrificed 24th day after injection, and the tumor tissues were fixed in $10 \%$ formalin, followed by paraffin infiltration and embedding. Five-micrometer-thick sections were mounted onto ProbeOn Plus microscope slides (Thermo Fisher Scientific), and immunohistochemical analysis was performed using the following primary antibodies; anti-ESM-1 (abx103810, 1:200, Abbexa, Cambridge, UK), ICAM-1 (sc-107, 1:100, Santa Cruz Biotechnology), anti-VCAM-1 (ab106778, 1:100, Abcam), anti-MMP-9 (ab38898, 1:200, Abcam), anti-HIF-1 $\alpha$ (ab2185 1:100, Abcam), anti-phospho-NF-kB (3033S, 1:100, Cell Signaling Technology), and anti-phospho-STAT-3 (9145S, 1:100, cell signaling) antibodies. Horseradish peroxidase-conjugated secondary antibodies were used, and then IHC staining was performed using an ABC kit (Vector Labs, Burlingame, CA, USA) and diaminobenzidine (DAB) according to the manufacturer's instructions. Following DAB staining, the sections were counterstained with Mayer's hematoxylin solution (Sigma-Aldrich) and observed under a light microscope (CKX41, Olympus). The animal experiment protocol was approved by the Institutional Animal Care and Use Committee at Gyeongsang National University (approval number: GLA-120208-M004, 08 February 2018), and all experiments were performed in compliance with institutional guidelines.

\subsection{Statistical Analysis}

Scanning densitometry was performed using an Image Master ${ }^{\circledR}$ VDS system (Pharmacia Biotech Inc., San Francisco, CA, USA), and intensity ratio of bands were presented in Table S1. GraphPad Prism 7 software (GraphPad Software, San Diego, CA, USA) was used to analyze all data. One-way ANOVA followed by the Newman-Keuls post hoc test were performed to compare various treatment groups. The data were presented as means \pm standard deviation (SD). A $p$-value $<0.05$ was considered statistically significant. 


\section{Conclusions}

ESM1 is known to be upregulated by inflammatory cytokines (IL-1 $\beta$, TNF- $\alpha$, and IFN- $\gamma$ ) and proangiogenic factors (VEGF-A and VEGF-C) and PI3K dependent pathway in cancer cell or endothelial cell [9-12]. However, the intracellular mechanisms induced by ESM1 are not well known. Kang et al. [17] reported that ESM1 plays a role in cell survival, cell cycle, migration, and invasion in colorectal cancer through affecting NF-KB and phospho-Akt pathways. Our results suggest for the first time that ESM-1 is the most overexpressed gene in RT-R-MDA-MB-231 cells compared to MDA-MB-231 cells and plays a critical role in tumorigenesis in breast cancer (Figure 7) through regulation of PDK, PKC, and ERK1/2 pathways and the subsequent activation of transcription factors HIF- $1 \alpha, \mathrm{NF}-\mathrm{kB}$, and STAT-3 to regulate adhesion molecules, MMPs, and VEGF. Based on these findings, ESM-1 may be a target molecule for treating $\mathrm{BC}$, especially TNBC.

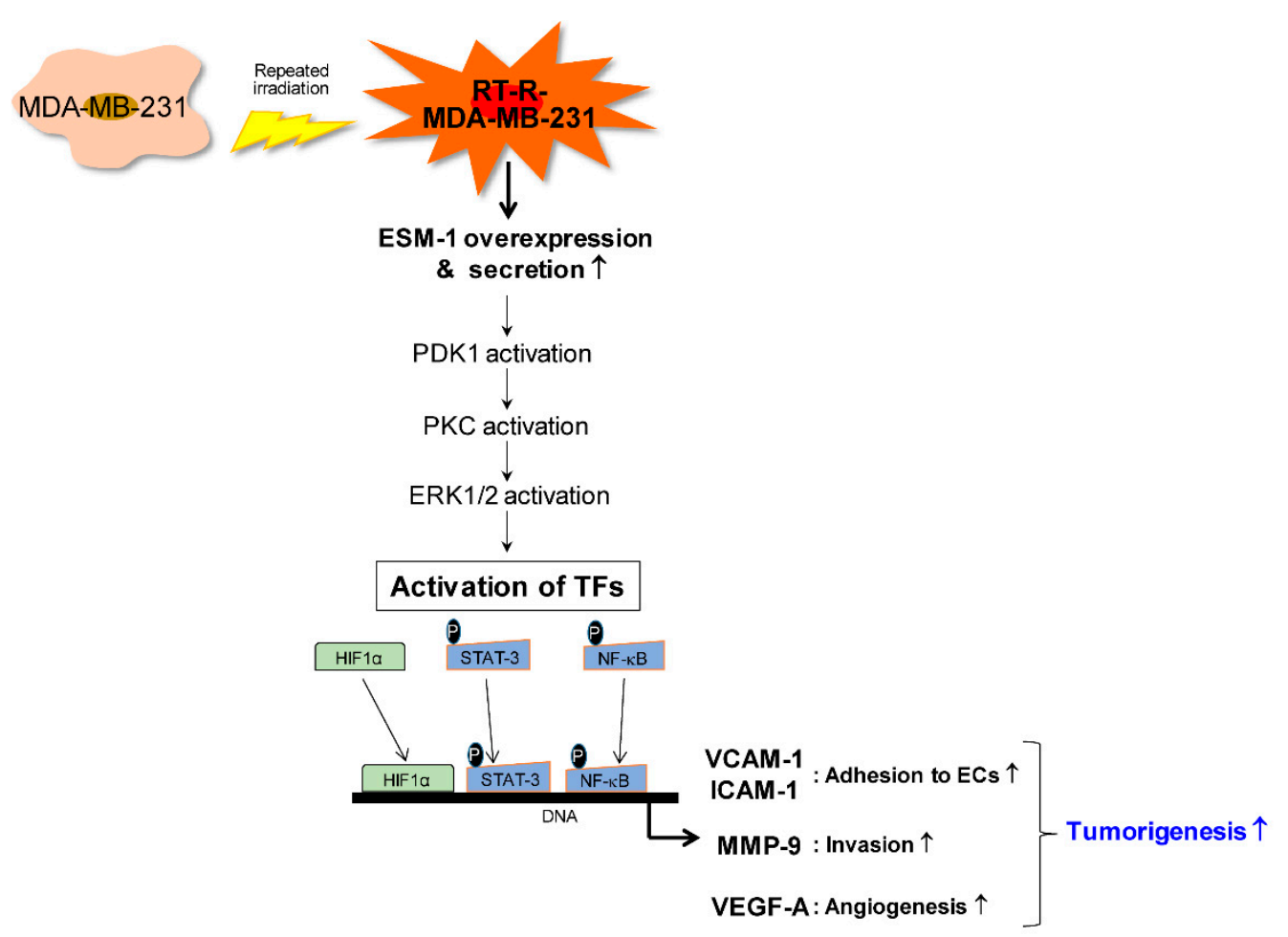

Figure 7. Schematic presentation of the mechanism by which ESM-1 plays an important role in the tumorigenesis of breast cancer cells.

Supplementary Materials: The following are available online at http://www.mdpi.com/2072-6694/12/6/1363/s1, Figure S1: Whole blot image from Figure 1A, Figure S2: Whole blot image from Figure 2A, Figure S3: Whole blot image from Figure 3A, Figure S4: Whole blot image from Figure 4A,C,E, Figure S5: Whole blot image from Figure 5A,C,E, Figure S6: Whole blot image from Figure 6A, Table S1: Intensity ratio of bands $(n=5)$.

Author Contributions: H.J. and T.R. performed the experiments, analyzed the data, and drafted the initial manuscript. Y.S.K. performed experiments and analyzed the data. S.W.P. and S.P.Y. discussed and provided important critical feedback about the data and methodology. H.J.K. designed the study, interpreted the data and revised the manuscript All authors have read and agreed to the published version of the manuscript.

Funding: This work was supported by Basic Science Research Program through the National Research Foundation of Korea (NRF) funded by the Ministry of Education, Science and Technology (2018R1A2B6001786), and by the Ministry of Science, ICT and Future Planning (NRF-2015R1A5A2008833).

Conflicts of Interest: The authors declare no conflict of interest. 


\section{Abbreviations}

\begin{tabular}{|c|c|}
\hline $\mathrm{BC}$ & breast cancer \\
\hline CCK-8 & cell counting kit- 8 \\
\hline CTRL & control \\
\hline DAB & 3,3'-diaminobenzidine tetrahydrochloride \\
\hline DAPI & 4',6-diamidino-2-phenyindole, dilactate \\
\hline DMEM & Dulbecco's modification of Eagle medium \\
\hline $\mathrm{EC}$ & endothelial cell \\
\hline ECL & enhanced chemiluminescence \\
\hline ER & estrogen receptors \\
\hline ERK & extracellular-signal-regulated kinase \\
\hline ESM-1 & endothelial cell-specific molecule 1 \\
\hline EV & empty vector \\
\hline FBS & fetal bovine serum \\
\hline HER2 & human epidermal growth factor receptor 2 \\
\hline HIF- $1 \alpha$ & hypoxia-inducible factor 1 alpha \\
\hline ICAM-1 & intercellular adhesion molecule-1 \\
\hline $\mathrm{IFN} \gamma$ & interferon gamma \\
\hline IHC & immunohistochemistry \\
\hline IL-1 $\beta$ & interleukin 1 beta \\
\hline MDA-MB-231 BR & MDA-MB-231 cells with a brain metastatic phenotype \\
\hline MMP & matrix metalloproteinase \\
\hline NF- $k B$ & nuclear factor kappa B \\
\hline PDK1 & phosphoinoisitide dependent kinase 1 \\
\hline PI3K & phosphoinositide 3-kinase \\
\hline PKC & protein kinase $\mathrm{C}$ \\
\hline PR & progesterone receptors \\
\hline $\mathrm{P} 2 \mathrm{Y}_{2} \mathrm{R}$ & P2Y purinergic receptor 2 \\
\hline RT-PCR & reverse transcription-polymerase chain reaction \\
\hline RT & radiotherapy \\
\hline RT-R & radiotherapy resistant \\
\hline SD & standard deviation \\
\hline SDS-PAGE & sodium dodecyl sulfate-polyacrylamide gel electrophoresis \\
\hline siRNA & small interfering RNA \\
\hline STAT-3 & signal transducer and activator of transcription 3 \\
\hline TNBC & triple negative breast cancer \\
\hline $\mathrm{TNF} \alpha$ & tumor necrosis factor alpha \\
\hline VCAM-1 & vascular cell adhesion molecule-1 \\
\hline VEGF & vascular endothelial growth factor \\
\hline
\end{tabular}

\section{References}

1. Bray, F.; Ferlay, J.; Soerjomataram, I.; Siegel, R.L.; Torre, L.A.; Jemal, A. Global cancer statistics 2018: GLOBOCAN estimates of incidence and mortality worldwide for 36 cancers in 185 countries. CA Cancer J. Clin. 2018, 68, 394-424. [CrossRef] [PubMed]

2. Harbeck, N.; Gnant, M. Breast cancer. Lancet 2017, 389, 1134-1150. [CrossRef]

3. Nguyen, Y.T.K.; Moon, J.Y.; Ediriweera, M.K.; Cho, S.K. Phenethyl isothiocyanate suppresses stemness in the chemo-and radio-resistant triple-negative breast cancer cell line MDA-MB-231/IR via downregulation of metadherin. Cancers 2020, 12, 268. [CrossRef] [PubMed]

4. Gray, M.; Turnbull, A.K.; Ward, C.; Meehan, J.; Martínez-Pérez, C.; Bonello, M.; Pang, L.Y.; Langdon, S.P.; Kunkler, I.H.; Murray, A.; et al. Development and characterisation of acquired radioresistant breast cancer cell lines. Radiat. Oncol. 2019, 14, 64. [CrossRef] 
5. Ko, Y.S.; Jin, H.; Lee, J.S.; Park, S.W.; Chang, K.C.; Kang, K.M.; Jeong, B.K.; Kim, H.J. Radioresistant breast cancer cells exhibit increased resistance to chemotherapy and enhanced invasive properties due to cancer stem cells. Oncol. Rep. 2018, 40, 3752-3762. [CrossRef] [PubMed]

6. Jin, H.; Ko, Y.W.; Kim, H.J. P2Y2R-mediated inflammasome activation is involved in tumor progression in breast cancer cells and in radiotherapy-resistant breast cancer. Int. J. Oncol. 2018, 53, 1953-1966. [CrossRef]

7. Maurage, C.A.; Adam, E.; Minéo, J.F.; Sarrazin, S.; Debunne, M.; Siminski, R.M.; Baroncini, M.; Lassalle, P.; Blond, S.; Delehedde, M. Endocan expression and localization in human glioblastomas. J. Neuropathol. Exp. Neurol. 2009, 68, 633-641. [CrossRef]

8. Béchard, D.; Gentina, T.; Delehedde, M.; Scherpereel, A.; Lyon, M.; Aumercier, M.; Vazeux, R.; Richet, C.; Degand, P.; Jude, B.; et al. Endocan is a novel chondroitin sulfate/dermatan sulfate proteoglycan that promotes hepatocyte growth factor/scatter factor mitogenic activity. J. Biol. Chem. 2001, 276, 48341-48349. [CrossRef]

9. Bechard, D.; Meignin, V.; Scherpereel, A.; Oudin, S.; Kervoaze, G.; Bertheau, P.; Janin, A.; Tonnel, A.; Lassalle, P. Characterization of the secreted form of endothelial-cell-specific molecule 1 by specific monoclonal antibodies. J. Vasc. Res. 2000, 37, 417-425. [CrossRef]

10. Lassalle, P.; Molet, S.; Janin, A.; Heyden, J.V.; Tavernier, J.; Fiers, W.; Devos, R.; Tonnel, A.B. ESM-1 is a novel human endothelial cell-specific molecule expressed in lung and regulated by cytokines. J. Biol. Chem. 1996, 271, 20458-20464. [CrossRef]

11. Rennel, E.; Mellberg, S.; Dimberg, A.; Petersson, L.; Botling, J.; Ameur, A.; Westholm, J.O.; Komorowski, J.; Lassalle, P.; Cross, M.J.; et al. Endocan is a VEGF-A and PI3K regulated gene with increased expression in human renal cancer. Exp. Cell Res. 2007, 313, 1285-1294. [CrossRef]

12. Shin, J.W.; Huggenberger, R.; Detmar, M. Transcriptional profiling of VEGF-A and VEGF-C target genes in lymphatic endothelium reveals endothelial-specific molecule-1 as a novel mediator of lymphangiogenesis. Blood 2008, 112, 2318-2326. [CrossRef]

13. Scherpereel, A.; Depontieu, F.; Grigoriu, B.; Cavestri, B.; Tsicopoulos, A.; Gentina, T.; Jourdain, M.; Pugin, J.; Tonnel, A.B.; Lassalle, P. Endocan, a new endothelial marker in human sepsis. Crit. Care Med. 2006, 34, 532-537. [CrossRef] [PubMed]

14. Grigoriu, B.D.; Depontieu, F.; Scherpereel, A.; Gourcerol, D.; Devos, P.; Ouatas, T.; Lafitte, J.J.; Copin, M.C.; Tonnel, A.B.; Lassalle, P. Endocan expression and relationship with survival in human non-small cell lung cancer. Clin. Cancer Res. 2006, 12, 4575-4582. [CrossRef] [PubMed]

15. Leroy, X.; Aubert, S.; Zini, L.; Franquet, H.; Kervoaze, G.; Villers, A.; Delehedde, M.; Copin, M.C.; Lassalle, P. Vascular endocan (ESM-1) is markedly overexpressed in clear cell renal cell carcinoma. Histopathology 2010, 56, 180-187. [CrossRef] [PubMed]

16. Abid, M.R.; Yi, X.; Yano, K.; Shih, S.C.; Aird, W.C. Vascular endocan is preferentially expressed in tumor endothelium. Microvasc. Res. 2006, 72, 138-145. [CrossRef] [PubMed]

17. Kang, Y.H.; Ji, N.Y.; Han, S.R.; Lee, C.I.; Kim, J.W.; Yeom, Y.I.; Kim, Y.H.; Chun, H.K.; Kim, J.W.; Chung, J.W.; et al. ESM-1 regulates cell growth and metastatic process through activation of NF- $\mathrm{kB}$ in colorectal cancer. Cell. Signal. 2012, 24, 1940-1949. [CrossRef]

18. Hatfield, K.J.; Lassalle, P.; Leiva, R.A.; Lindås, R.; Wendelboe, Ø.; Bruserud, Ø. Serum levels of endothelium-derived endocan are increased in patients with untreated acute myeloid leukemia. Hematology 2011, 16, 351-356. [CrossRef]

19. Sagara, A.; Igarashi, K.; Otsuka, M.; Kodama, A.; Yamashita, M.; Sugiura, R.; Karasawa, T.; Arakawa, K.; Narita, M.; Kuzumaki, N.; et al. Endocan as a prognostic biomarker of triple-negative breast cancer. Breast Cancer Res. Treat. 2017, 161, 269-278. [CrossRef]

20. Scherpereel, A.; Gentina, T.; Grigoriu, B.; Sénéchal, S.; Janin, A.; Tsicopoulos, A.; Plénat, F.; Béchard, D.; Tonnel, A.B.; Lassalle, P. Overexpression of endocan induces tumor formation. Cancer Res. 2003, 63, 6084-6089.

21. Intlekofer, A.M.; Finley, L.W.S. Metabolic signatures of cancer cells and stem cells. Nat. Metab. 2019, 1, 177-188. [CrossRef] [PubMed]

22. Benedicto, A.; Romayor, I.; Arteta, B. Role of liver ICAM-1 in metastasis. Oncol. Lett. 2017, 14, $3883-3892$. [CrossRef] [PubMed]

23. Kong, D.H.; Kim, Y.K.; Kim, M.R.; Jang, J.H.; Lee, S. Emerging Roles of Vascular Cell Adhesion Molecule-1 (VCAM-1) in Immunological Disorders and Cancer. Int. J. Mol. Sci. 2018, 19, 1057. [CrossRef] [PubMed] 
24. Xia, Y.; Shen, S.; Verma, I.M. NF-kB, an active player in human cancers. Cancer Immunol. Res. 2014, 2, 823-830. [CrossRef] [PubMed]

25. Multhoff, G.; Molls, M.; Radons, J. Chronic inflammation in cancer development. Front. Immunol. 2012, 2, 98. [CrossRef]

26. Karagiota, A.; Kourti, M.; Simos, G.; Mylonis, I. HIF-1 $\alpha$-derived cell-penetrating peptides inhibit ERK-dependent activation of HIF-1 and trigger apoptosis of cancer cells under hypoxia. Cell. Mol. Life Sci. 2019, 76, 809-825. [CrossRef]

27. Wang, X.; Chen, Q.; Xing, D. Focal adhesion kinase activates NF-kB via the ERK1/2 and p38MAPK pathways in amyloid- $325-35-$ Induced apoptosis in PC12 cells. J. Alzheimer's Dis. 2012, 32, 77-94. [CrossRef]

28. Chen, B.; Liu, J.; Ho, T.T.; Ding, X.; Mo, Y.Y. ERK-mediated NF-kB activation through ASIC1 in response to acidosis. Oncogenesis 2016, 5, e279. [CrossRef]

29. Taniguchi, K.; Karin, M. NF-кB, inflammation, immunity and cancer: Coming of age. Nat. Rev. Immunol. 2018, 18, 309-324. [CrossRef]

30. Robinson, R.L.; Sharma, A.; Bai, S.; Heneidi, S.; Lee, T.J.; Kodeboyina, S.K.; Patel, N.; Sharma, S. Comparative STAT3-regulated gene expression profile in renal cell carcinoma subtypes. Front. Oncol. 2019, 9, 72. [CrossRef]

31. Ding, D.; Han, S.; Zhang, H.; He, Y.; Li, Y. Predictive biomarkers of colorectal cancer. Comput. Biol. Chem. 2019, 83, 107106. [CrossRef] [PubMed]

32. Ji, N.Y.; Kim, Y.H.; Jang, Y.J.; Kang, Y.H.; Lee, C.I.; Kim, J.W.; Yeom, Y.I.; Chun, H.K.; Choi, Y.H.; Kim, J.H.; et al. Identification of endothelial cell-specific molecule-1 as a potential serum marker for colorectal cancer. Cancer Sci. 2010, 101, 2248-2253. [CrossRef]

33. Jin, H.; Eun, S.Y.; Lee, J.S.; Park, S.W.; Lee, J.H.; Chang, K.C.; Kim, H.J. P2Y2 receptor activation by nucleotides released from highly metastatic breast cancer cells increases tumor growth and invasion via crosstalk with endothelial cells. Breast Cancer Res. 2014, 16, R77. [CrossRef] [PubMed]

34. Arsenic, R. Immunohistochemical analysis of PDK1 expression in breast cancer. Diagn. Pathol. 2014, 9, 1-3. [CrossRef] [PubMed]

35. Raimondi, C.; Falasca, M. Targeting PDK1 in Cancer. Curr. Med. Chem. 2011, 18, 2763-2769. [CrossRef]

36. Du, J.; Yang, M.; Chen, S.; Li, D.; Chang, Z.; Dong, Z. PDK1 promotes tumor growth and metastasis in a spontaneous breast cancer model. Oncogene 2016, 35, 3314-3323. [CrossRef]

37. Islam, S.M.A.; Patel, R.; Acevedo-Duncan, M. Protein Kinase C- $\zeta$ stimulates colorectal cancer cell carcinogenesis via PKC-乙/Rac1/Pak1/ß-Catenin signaling cascade. Biochim. Biophys. Acta Mol. Cell Res. 2018, 1865, 650-664. [CrossRef]

38. Cooke, M.; Magimaidas, A.; Casado-Medrano, V.; Kazanietz, M.G. Protein kinase C in cancer: The top five unanswered questions. Mol. Carcinog. 2017, 56, 1531-1542. [CrossRef]

39. Hwang, Y.P.; Jeong, H.G. Metformin blocks migration and invasion of tumour cells by inhibition of matrix metalloproteinase- 9 activation through a calcium and protein kinase $C \alpha$-dependent pathway: Phorbol-12-myristate-13-acetate-induced/ extracellular signal-regulated kinase/activa. Br. J. Pharmacol. 2010, 160, 1195-1211. [CrossRef]

40. Bartholomeusz, C.; Gonzalez-Angulo, A.M.; Liu, P.; Hayashi, N.; Lluch, A.; Ferrer-Lozano, J.; Hortobágyi, G.N. High ERK protein expression levels correlate with shorter survival in triple-negative breast cancer patients. Oncologist 2012, 17, 766-774. [CrossRef]

(C) 2020 by the authors. Licensee MDPI, Basel, Switzerland. This article is an open access article distributed under the terms and conditions of the Creative Commons Attribution (CC BY) license (http://creativecommons.org/licenses/by/4.0/). 